\title{
PARADA EREANIMAÇÃO CARDIORRESPIRATÓRIA: CONHECIMENTO DO ENFERMEIRO BASEADO NAS DIRETRIZES DA AMERICAN HEART ASSOCIATION 2015
}

Francisco Railson Bispo de Barros 1 , Manoel Luis Neto²

Objetivos: Objetivo: avaliar o conhecimento do especialista em formação do curso de Cardiologia e Hemodinâmica no que se refere ao atendimento emergencial à parada cardiorrespiratória, segundo as novas diretrizes da American Heart Association - 2015. Metodologia: estudo descritivo/exploratório, com abordagem quantitativa. A coleta de dados foi realizada entre março e abril de 2017, por meio da aplicação de um questionário estruturado em pós-graduandos. Os dados foram analisados por meio da estatística descritiva simples. Resultados: da amostra de 25 pós-graduandos, 20 (80\%) tinha conhecimento para identificar uma parada cardiorrespiratória e 21 (84\%) indicaram qual a conduta correta após a detecção deste evento, 20 (80\%) referiram que já realizaram cursos sobre o tema e 23 (92\%) buscaram melhores informações sobre o tema na literatura. Conclusão: os pós-graduandos possuem conhecimento suficiente sobre o tema proposto, apresentando interesse na qualificação técnico-científica.

Descritores: Parada Cardiaca; Enfermagem; Ressuscitação Cardiopulmonar.

\section{CARDIORESPIRATORY ARREST AND RESUSCITATION: NURSE'S KNOWLEDGE BASED ON AMERICAN HEART ASSOCIATION GUIDELINES 2015}

Objective: to evaluate the knowledge of the specialist in the training of Cardiology and Hemodynamics in emergency cardiac arrest, according to the new guidelines of the American Heart Association - 2015. Methodology: descriptive / exploratory study, with a quantitative approach. Data collection was performed between March and April 2017, through the application of a structured questionnaire, the final sample being composed of 25 post-graduate students obtained for convenience. Data were analyzed using simple descriptive statistics. Results: of the sample of 25 participants, 20 (80\%) had knowledge to identify a cardiorespiratory arrest and 21 (84\%) indicated the correct behavior after the detection of this event, 20 (80\%) reported having already taken courses on the subject and 23 (92\%) sought better information on the subject in the literature. Conclusion: the postgraduate students have sufficient knowledge about the proposed topic, presenting an interest in the technical-scientific qualification.

Descriptors: Cardiac Arrest; Nursing; Cardiopulmonary Resuscitation.

\section{PARADA Y REANIMACIÓN CARDIORRESPIRATORIA: CONOCIMIENTO DEL ENFERMERO BASADO}

\section{EN LAS DIRECTRICES DE LAAMERICAN HEART ASSOCIATION 2015}

Objetivo: evaluar el conocimiento del especialista en formación del curso de Cardiología y Hemodinámica en lo que se refiere a la atención de emergencia a la parada cardiorrespiratoria, según las nuevas directrices de la American Heart Association 2015. Metodología: estudio descriptivo / exploratorio, con abordaje cuantitativo. La recolección de datos fue realizada entre marzo y abril de 2017, a través de la aplicación de un cuestionario estructurado, siendo la muestra final compuesta por 25 post graduados obtenida por conveniencia. Los datos se analizaron mediante la estadistica descriptiva simple. Resultados: de la muestra de 25 participantes, 20 (80\%) tenian conocimiento para identificar una parada cardiorrespiratoria y 21 (84\%) indicaron cuál es la conducta correcta después de la detección de este evento, 20 (80\%) mencionaron que ya realizaron cursos sobre el tema y 23 (92\%) buscaron mejores informaciones sobre el tema en la literatura. Conclusión: los post-graduandos poseen conocimiento suficiente sobre el tema propuesto, presentando interés en la calificación técnico-científica.

Descriptores: Parada Cardiaca; Enfermería; Resucitación Cardiopulmonar 


\section{INTRODUÇÃO}

As Doenças Cardiovasculares (DCV) são a principal causa de morbimortalidade nos países em desenvolvimento e também naqueles desenvolvidos. Atualmente, no Brasil, são responsáveis por cerca de $20 \%$ de todas as mortes em indivíduos de 30 anos, onde cerca de 820 pessoas morrem a cada dia, vítimas de doenças cardiovasculares. Apesar do progresso, quando comparados a outros países, inclusive vizinhos latino-americanos, nossa mortalidade por DCV ainda se mostra uma das maiores do mundo ${ }^{(1)}$.

A Morte Súbita Cardíaca (MSC) é uma intercorrência cardiovascular inesperada que constitui gravíssima ameaça à vida das pessoas, principalmente das que sofrem um colapso cardíaco não presenciado. No Brasil, estima-se anualmente 300 mil vítimas de morte súbita, superando todas as mortes por sindrome de imunodeficiência adquirida, câncer de mama e pulmão e acidente vascular cerebra ${ }^{(1-2)}$.

Dados epidemiológicos constatam que a causa predominante de MSC tem origem cardiovascular, $70 \%$ a $80 \%$ dos casos, seguida da neurovascular com $10 \%$ a $15 \%$. A MSC decorre de alguma arritmia em $88 \%$ dos casos, desses, $60 \%$ a $80 \%$ incluem ritmos desfibriláveis, como Taquicardia Ventricular (TV) sem pulso ou Fibrilação Ventricular (FV). As taxas de sobrevivência a uma Parada Cardiorrespiratória (PCR) dependem da eficácia do atendimento, bem como do tempo transcorrido entre chamada e choque ${ }^{(3)}$.

Para que $o$ atendimento a uma pessoa nessa situação seja feito com sucesso, há a necessidade de reconhecimento precoce dos sinais de PCR, rápida ativação de sistema de atendimento de emergência e pronta implementação do suporte básico e avançado de vida. As diretrizes que orientam as ações em situações de emergência buscam facilitar e aperfeiçoar a tomada de decisão frente à $\mathrm{PCR}^{(4)}$.

Quinquenalmente a American Heart Associeation (AHA) lança novas diretrizes de RCP, as quais se baseiam em um rigoroso processo internacional de avaliação de evidências. Segundo a entidade o atendimento à PCR divide-se em Suporte Básico de Vida (SBV), que compreende um conjunto de técnicas sequenciais caracterizadas por compressões torácicas, abertura das vias aéreas, respiração artificial e desfibrilação e Suporte Avançado de Vida (SAV) que consiste na manutenção do SBV, com a administração de medicamentos e o tratamento da causa da $\mathrm{PCR}^{(5)}$.

Neste sentido, ao considerar a PCR como uma emergência clínica, na qual o objetivo primordial consiste em preservar a vida, restabelecer as funções fisiológicas, aliviar o sofrimento e diminuir incapacidades, a assistência deve ser realizada com eficiência e eficácia. Perante o contexto destaca-se a figura do enfermeiro, profissional muitas vezes responsável por reconhecer a PCR, iniciar o SBV e auxiliar no SAV(3).
A atualização permanente quanto às novas diretrizes da RCP é essencial para reduzir a morbimortalidade dos pacientes de qualquer idade, assim como, as consequências neurológicas acarretadas pela demora ou ineficiência do atendimento. $\mathrm{O}$ conhecimento do profissional enfermeiro é imprescindivel, pois sua competência é um fator crítico na determinação do sucesso da assistência e fundamentação da ação executada, características determinantes e condicionantes que contribuem para a sobrevivência inicial de um paciente em súbita PCR.

Assim, é relevante responder a pergunta da pesquisa: qual o nível de conhecimento do futuro enfermeiro especialista em cardiologia e hemodinâmica no que se refere ao atendimento emergencial à parada cardiorrespiratória, segundo as novas diretrizes da American Heart Association - 2015.

\section{METODOLOGIA}

Trata-se de um estudo descritivo/exploratório, com abordagem quantitativa, desenvolvido em uma instituição de educação e formação profissional de caráter privada, localizada na cidade de Manaus - AM, região Norte do Brasil. A população estudada foi constituída por 36 profissionais enfermeiros, os quais integram a primeira turma do curso de Pós-graduação de Enfermagem em Cardiologia e Hemodinâmica da referida instituição.

Foram considerados os seguintes critérios de inclusão: os enfermeiros deveriam estar devidamente matriculados no referido curso no período da coleta de dados, ter disponibilidade para participar da pesquisa e aceitar participar voluntariamente. Assim, o estudo foi desenvolvido com um total de 25 participantes.

A coleta de dados ocorreu no período de março a abril de 2017, após a prévia autorização da coordenação da instituição e aprovação (Parecer № 1.928.784/17) do projeto pelo Comitê de Ética em Pesquisa da Universidade Estadual do Amazonas com base no que é prevista pela Resolução № 466/2012 do Conselho Nacional de Saúde (CNS).

O instrumento de coleta de dados foi um questionário estruturado e adaptado dos instrumentos já existentes na literatura ${ }^{(2,4,6-7,13-14)}$, com variáveis sociodemográficas e sobre a avaliação inicial na PCR e responsividade da vítima; abertura das vias aéreas e manobras de respiração: avaliação do pulso carotídeo e compressões torácicas; utilização do Desfibrilador Externo Automático; terapia medicamentosa.

As informações obtidas foram armazenadas no software aplicativo Microsoft Excel 2007® e, posteriormente, foram analisadas estatisticamente, calculando-se as frequências absolutas e relativas para todas as variáveis estudadas. 


\section{RESULTADOS}

A amostra foi constituida por $25(69,4 \%)$ pós-graduandos do curso de Enfermagem em Cardiologia e Hemodinâmica. Do total de enfermeiros, sete $(19,4 \%)$ se recusaram a participar e quatro $(11,1 \%)$ estavam inadim- plentes com a instituição, resultando no trancamento da matrícula.

Na variável idade dos enfermeiros, a mínima encontrada foi de 23 anos e máxima de 50 anos, com média de 32,28 anos, cuja maioria, 23 (92\%) era do gênero feminino (Tabela 1).

Tabela 1 - Distribuição dos dados sociodemográficos dos pós-graduandos. Manaus, AM, Brasil, 2017.

\begin{tabular}{|c|c|c|}
\hline Variável & no & $\%$ \\
\hline \multicolumn{3}{|l|}{ Faixa etária (anos) } \\
\hline 23 a 30 & 18 & 72,0 \\
\hline 31 a 40 & 5 & 20,0 \\
\hline 41 a 50 & 2 & 8,0 \\
\hline \multicolumn{3}{|l|}{ Sexo } \\
\hline Masculino & 2 & 8,0 \\
\hline Feminino & 23 & 92,0 \\
\hline Total & 25 & 100 \\
\hline
\end{tabular}

Com relação ao conhecimento teórico dos enfermeiros acerca dos sinais clínicos de uma PCR, constatou-se que dos 25 entrevistados, 20 (80\%) afirmaram que essa situação caracteriza-se pela perda da consciência e pela ausência do pulso carotídeo. Ao serem questionados sobre a pri- meira conduta a ser tomada ao se deparar com uma pessoa que estivesse apresentando os sinais clínicos de PCR, 21 (84\%) mencionaram que deveria ser checado a responsividade da vítima e 3 (16\%) afirmaram que deveria ser checada a respiração da vítima (Tabela 2 ).

Tabela 2 - Conhecimento dos pós-graduandos a respeito dos sinais clínicos e medidas a serem tomadas frente a PCR. Manaus, AM, Brasil, 2017.

\begin{tabular}{|c|c|c|}
\hline Variáveis & n으 & $\%$ \\
\hline \multicolumn{3}{|l|}{ Sinais clinicos de PCR } \\
\hline Ausência de qualquer pulso e perda da consciência & 4 & 16,0 \\
\hline Perda da consciência & 1 & 4,0 \\
\hline \multicolumn{3}{|l|}{ Primeira ação } \\
\hline Checar responsividade & 3 & 16,0 \\
\hline Checar respiração & 0 & 0,0 \\
\hline Chamar ajuda & 21 & 84,0 \\
\hline
\end{tabular}

Quando questionados sobre os ritmos cardíacos característicos de uma $\mathrm{PCR}$ que requerem a aplicação de choque elétrico, constatou-se que ouve prevalência dos ritmos de TV e FV. Acerca do conhecimento sobre o algo- ritmo do Suporte Básico de Vida, 23 (92\%) enfermeiros afirmaram que a sequência correta é $C A B D$, ou seja, checar pulso (C), abrir vias aéreas (A), manter boa ventilação (B) e choque elétrico (D), este por sua vez quando da chegada do 
Suporte Avançado de Vida. Com relação às compressões torácicas e a oferta de ventilação durante a PCR com a assistência de dois socorristas 24 (96\%) dos entrevistados afirmaram que a relação deve ser de 30 compressões para 2 ventilações $(30 \times 2)$, conforme os dados apresentados na Tabela 3.

Tabela 3 - Conhecimento dos pós-graduandos a respeito dos ritmos cardíacos característicos de uma PCR que requerem a aplicação de choque pelo desfibrilador. Manaus, AM, Brasil, 2017.

\begin{tabular}{|c|c|c|}
\hline Variáveis & $\mathrm{n}$ 은 & $\%$ \\
\hline \multicolumn{3}{|l|}{ Ritmos cardiacos chocáveis } \\
\hline TV, FV, AESP Assistolia & 2 & 8,0 \\
\hline TV e FV & 18 & 72,0 \\
\hline FV, TV e AESP & 3 & 12,0 \\
\hline Assistolia e TV & 2 & 8,0 \\
\hline \multicolumn{3}{|l|}{ Algoritmo da RCP } \\
\hline CABD & 23 & 92,0 \\
\hline$A B C D$ & 2 & 8,0 \\
\hline$B C A D$ & 0 & 0,0 \\
\hline DABC & 0 & 0,0 \\
\hline \multicolumn{3}{|l|}{ Compressões torácicas $\mathrm{x}$ ventilação } \\
\hline $30 \times 2$ & 24 & 96,0 \\
\hline $15 \times 2$ & 1 & 4,0 \\
\hline $30 \times 1$ & 0 & 0,0 \\
\hline $15 \times 1$ & 0 & 0,0 \\
\hline Total & 25 & 100 \\
\hline
\end{tabular}

Com relação à frequência das compressões torácicas que devem ser ministradas na vítima de PCR e a profundidade dessas compressões no tórax, a maioria dos 25 entrevistados, 23 (92\%) afirmaram que deveria ser feita entre 100 e 120 compressões por minuto, predominando compressão torácica numa profundida entre 2 a 2,4 polegadas, o equivalente entre 5 e $6 \mathrm{~cm}$ respectivamente (Tabela 4).

Tabela 4 - Conhecimento dos pós-graduandos a respeito das compressões torácicas. Manaus, AM, Brasil, 2017.

\begin{tabular}{|c|c|c|}
\hline Variáveis & $\mathrm{n}$ 은 & $\%$ \\
\hline \multicolumn{3}{|l|}{ Frequência de compressões por minuto } \\
\hline Até 100 & 2 & 8 \\
\hline Entre 60 e 100 & 0 & 0 \\
\hline \multicolumn{3}{|l|}{ Profundidade exercida no tórax (cm) } \\
\hline Entre 3 e 4 & 0 & 0 \\
\hline Entre 4 e 7 & 1 & 4 \\
\hline
\end{tabular}


Os enfermeiros foram avaliados quanto ao interesse que possuem acerca do tema através de dois pontos considerados, para esta pesquisa, cardeais: interesse em realizar cursos de qualificação e busca espontânea por literatura científica específica sobre o tema. Quando questionados sobre a realização de cursos sobre o assunto, $80 \%$ dos en- fermeiros afirmaram que já realizaram curso preparatório para as situações de RCP, enquanto $20 \%$ mencionaram que não participaram de cursos que envolviam a temática, 92\% (23) dos enfermeiros referiram que procuram aprofundar o conhecimento acerca da PCR/RCP por meio da leitura de trabalhos científicos (Tabela 5).

Tabela 5 - Conhecimento dos pós-graduandos segundo interesse que possuem acerca do tema. Manaus, AM, Brasil, 2017.

\begin{tabular}{lcc}
\multicolumn{1}{c}{ Variáveis } & no & \% \\
\hline Realização de cursos sobre RCP/PCR & & 80 \\
Sim & 20 & 20 \\
Não & 5 & 23 \\
\hline Leitura de literatura especifica & 2 & 82 \\
Sim & 25 & 100 \\
Não & 25 \\
\hline Total & \\
\hline
\end{tabular}

\section{DISCUSSÃO}

Foi observado no presente estudo que o número de mulheres cursando a pós-graduação é superior ao de homens. Em um estudo realizado com 91 pós-graduandos atuando em unidades não hospitalares de atendimento à urgência e emergência, com objetivo de avaliar o conhecimento teórico dos enfermeiros sobre RCP, também foi observada maior prevalência do sexo feminino nessa profissão(7).

O objetivo da avaliação inicial da vítima de PCR é a detecção imediata dos sinais clínicos sugestivos desse quadro. Nesse sentido, a primeira conduta a ser tomada pelo socorrista, após a análise do cenário, é a avaliação do nível de consciência e do pulso carotídeo da vítima por no máximo 10 segundos, que apresentará inconsciência e ausência de pulso. Nesse estudo, mais de $2 / 3$ dos participantes respondeu corretamente a essa questão. Estudo desenvolvido com enfermeiros e médicos de um hospital público com o objetivo de avaliar o conhecimento teórico sobre a mesma temática do estudo proposto também identificou um elevado índice de satisfação para a detecção de uma PCR, no qual 78,9\% dos profissionais indicaram uma adequada avaliação do referido quadro clínico(2).

Após a detecção de uma PCR, o profissional da saúde deve imediatamente solicitar o Serviço Médico de Emergência(5), no caso do Brasil o Serviço de Atendimento Móvel de Urgência (SAMU 192). Nesse estudo foi constatado que a maioria dos pós-graduandos sabe que a primeira ação após a identificação da PCR é solicitar ajuda. No estudo citado anteriormente, observou-se que $75,7 \%$ dos profissionais responderam corretamente a essa questão, o que caracteriza um considerado nível de conhecimento quanto ao atendimento inicial ${ }^{(2)}$.
Seguindo o Guideline da AHA, os ritmos cardíacos que são chocáveis na PCR são a fibrilação e a taquicardia ventricular ${ }^{(5)}$. Nesse estudo a predominância de assertivas, corrobora com o resultado encontrado no estudo desenvolvido com 11 enfermeiros de um hospital municipal de São Paulo, que demonstrou que $66 \%$ dos enfermeiros tinham conhecimento adequado sobre essa conduta(3).

Grande parte das vítimas de PCR encontra-se no ritmo cardiaco de fibrilação ventricular ou taquicardia ventricular sem pulso. Para essas vítimas, os elementos iniciais do SBV são as compressões torácicas e a desfibrilação precoce. Entretanto, assim que do DEA estiver disponível, este passa a ser a prioridade de uso, uma vez que estes ritmos exigem a administração de choques, ou seja, cargas de desfibrilação de alta energia não sincronizadas ${ }^{(5)}$.

Desde as diretrizes de 2010 da AHA, reforçadas em 2015, as manobras de RCP realizadas pelo socorrista devem seguir a sequência mnemônica CABD (Circulation/Circulação - realizar as compressões torácicas; Airway/Via aérea - realizar a abertura da via aérea; Breathing/Respiração - realizar ventilação e Defibrilation/Desfibrilação - choque FV/TV sem pulso). Constatou-se nesse estudo que mais da metade dos entrevistados sabe a sequência correta do algoritmo a seguir nos casos de PCR, indicando atualização no conhecimento científico acerca de sua atuação nessas situações.

No que se refere à relação entre compressão torácica e a oferta de ventilação artificial com a assistência de dois socorristas, o Guideline-2015 recomenda que sejam realizadas 30 compressões intercaladas com 2 ventilações ${ }^{(5)}$. O que foi observado no presente estudo é que quase a totalidade dos 
entrevistados respondeu corretamente, indicando uma adequada assimilação do conteúdo teórico-prático.

Neste estudo, observou-se que a maioria dos pós-graduandos afirmou que a frequência das compressões deve ser entre 100 e 120 por minuto numa profundidade ideal de $5 \mathrm{~cm}$, mas não superior a $6 \mathrm{~cm}$. A literatura científica e a AHA delimitaram que devem ser realizadas compressões torácicas com profundidade nas referências supracitadas para que a RCP seja considerada de boa qualidade, garantindo a manutenção da circulação e da oxigenação do músculo cardíaco, responsáveis pela condução de oxigênio aos órgãos vitais, mas principalmente ao cérebro(5-10,13,15).

Na maioria dos estudos, a aplicação de mais compressões está associada a maiores taxas de sobrevivência, ao passo que a aplicação de menos compressões esta associada a uma menor sobrevivência ${ }^{(6-10,13,15)}$. A importância de comprimir o tórax numa profundidade de, no mínimo, $5 \mathrm{~cm}$ justifica-se pelo fato que desta forma se criará um fluxo sanguíneo maior, principalmente por aumentar a pressão intratorácica e comprimir diretamente o coração(b).

A busca de informações relativas à PCR e a capacitação para atuação nesses casos por meio da utilização das manobras de RCP devem ser consideradas prioridade para os profissionais da saúde, sobretudo da enfermagem ${ }^{(13)}$. De um modo geral, foi observado que os pós-graduandos têm um qualificado nível de conhecimento em diversos pontos relacionados à temática, tendo em vista a busca pela qualificação profissional.

Nesse contexto, acredita-se que a busca de cursos é um ótimo coadjuvante para maior capacitação e atualização para que os profissionais, neste caso futuros Enfermeiros Cardiologistas, tenham melhor conhecimento teórico-prático e, consequentemente, melhor desempenho durante um possivel atendimento, contribuindo para a maior sobrevida da vítima ${ }^{(15)}$.

\section{CONSIDERAÇÕES FINAIS}

Este estudo permitiu concluir que os enfermeiros pósgraduandos do curso de Enfermagem em Cardiologia e Hemodinâmica possuem um alto nivel de conhecimento sobre a Parada Cardiorrespiratória e as manobras de Ressuscitação Cardiopulmonar recomendadas pelo Guideline da American Heart Association - 2015, desde a conduta após a detecção da PCR, até a chegada e instalação dos cuidados avançados.

O estudo também possibilitou identificar que o enfermeiro, no âmbito de seu trabalho, é um dos principais profissionais de saúde com autonomia e capacitação para agir no momento de uma PCR, sendo este, de fundamental importância, assim como toda a equipe de enfermagem, manter-se atualizados e capacitados para prestar assistência às prováveis emergências e proporcionar capacitações teóricas e práticas com os outros membros da equipe.

\section{REFERÊNCIAS}

1. Quilici AP, Bento AM, Ferreira FG, Cardoso LF, Moreira RSL, Silva SC. Enfermagem em cardiologia. 2o ed. São Paulo: Atheneu; 2015.

2. Cunha CM, Toneto MAS, Pereira EBS. Conhecimento teórico dos enfermeiros de hospital público sobre reanimação cardiopulmonar. Bioscience Journal. 2013:29(5):1395-1402.

3. Credo PFD, Boostel R, Felix JVC. Conhecimento da equipe multiprofissional de saúde baseado nas diretrizes da American Heart Association-2010. Journal of nursing UFPE. 2015:9(10):9423-30.

4. Silva DV, Jesus APS, Lima AA, Santos MAS, Alves SL. Conhecimento de graduandos em enfermagem sobre suporte básico de vida. Rev baiana enferm. 2015:29(2):125-34.

5. American Heart Association. Destaques das diretrizes da American Heart Association 2015 para RCP e ACE. [versão em Português] [Internet]. 2010 [cited 2016 Aug 10];1-28. Available from https://eccguidelines.heart.org/wp-content/uploads/2015/10/2015-AHAGuidelines-Highlights-Portuguese.pdf

6. Oliveira SS, Santos JO, Zeitoun SS. Suporte Básico de Vida: avaliação do conhecimento dos graduandos de enfermagem. Journal health scien inst. 2014:32(1):53-58.

7. Ferreira JVB, Ferreira SMB, Casseb GB. Perfil e Conhecimento Teórico de Médicos e Enfermeiros em Parada Cardiorrespiratória, municipio de Rio Branco, AC. Rev bras cardiol. 2012;25(6):464-70.

8. Phtls. National Association of Emergency Medical Technicians. PHTLS: Atendimento pré-hospitalar ao traumatizado: básico e avançado. 8 ed. Rio de Janeiro: Elsevier; 2016.
9. Pereira DS, Vieira AKI, Ferreira AM, Bezerra AMF, Bezerra WKT. Atuação do Enfermeiro Frente à Parada Cardiorrespiratória (PCR). Rev bras educ saúde. 2015:5(3):08-17.

10. Lima CA, Lafetá AFM, Paula BP, Leite LES, Paiva PA, Leão HM, Barbosa HÁ, Figueiredo ML, Diamantino AM, Ruas EFG. Suporte avançado de vida na parada cardiorrespiratória: Aspectos teóricos e assistenciais. Rev UVRV. 2015;13(1):653-63.

11. Brasil. Decreto-Lei n.o 94.406, de 08 de Junho de 1987. Regulamenta a Lei n. 97.498 , de 25 de Junho de 1986, que dispõe sobre o exercício da enfermagem, e dá outras providências. [citado 2016 Set 20]. Disponivel em: http://corensp.org.br/072005/

12. Cofen. Conselho Federal de Enfermagem - COFEN. Resolução COFEN 311/2007 - Código de Ética dos Profissionais de Enfermagem. Rio de Janeiro, 8 de fevereiro de 2007. [citado 2016 Set 20]. Disponivel em: http://se.corens.portalcofen.gov.br/codigo-de-etica-resolucaocofen-3112007

13. Alves, CA, Barbosa CNS, Faria HTG. Parada cardiorrespiratória e enfermagem: o conhecimento acerca do suporte básico de vida. Cogitare enferm. 2013;18(2):296-301.

14. Polit DF, Beck CT. Fundamentos de Pesquisa em Enfermagem: Avaliação de Evidências para a Prática da Enfermagem. Artmed Editora; 2016.

15. Almeida AO, Araújo IEM, Dalri MCB, Araújo S. Conhecimento teórico dos enfermeiros sobre parada e ressuscitação cardiopulmonar, em unidades não hospitalares de atendimento à urgência e emergência. Rev latino-am enferm. 2011:19(2):261-8. 